\title{
Monitoring Suhu Proses Sangrai Biji Kopi
}

\section{Temperature Monitoring For Coffe Seed Rosting}

\author{
Roza Susanti, Zas Ressy Aidha \& Fedri Tri Satrio \\ Jurusan Teknik Elektro Politeknik Negeri Padang Kampus Limau Manis Padang 25163 \\ Telp 0751-72590 Fax 0752-72576 Email: rozaaznir@ gmail.com
}

\begin{abstract}
Temperature set of the coffee bean roasting to get the roasting temperature of arabica using thermocouple temperature cencor. Temperature monitoring is controlled by microcontroller. The suitable temperature set of roasting process determine the temperature of three conditions, they are light roast, medium roast, and dark roast. Roasting temperature set of the coffee bean have a goal to get the best quality of coffee bean.
\end{abstract}

Keyword : temperature setting, roasting and arabika coffee.

\section{PENDAHULUAN}

Salah satu hasil produk bumi di Indonesia adalah tanaman kopi. Negara Indonesia merupakan salah satu produsen kopi terbesar ke tiga setelah Negara Brazil dan Vietnam (Mentri Pertanian,2014). Dari data statistik yang lansir oleh Direktorat Jenderal Perkebunan Indonesia (2014), Negara Indonesia mempunyai hasil produk kopi yang besar dan terus meningkat. Perkembangan ini dapat dilihat dari hasil produksi pada tahun 2013 hingga tahun 2015 lalu. Jumlah total produksi pada tahun 2013 yaitu 675.881 ton, tahun 2014 yaitu 685.089 ton dan tahun 2015 yaitu 739.005 ton.

Proses pengolahan biji kopi salah satunya adalah pengolahan sekunder atau pembuatan bubuk kopi. Penyangraian merupakan salah satu proses olahan pebuatan bubuk kopi. Proses sangrai ini akan bertujuan mensintesakan senyawasenyawa pembentuk aroma dan citarasa khas kopi yang berada di dalam biji kopi. Proses penyangraian ini salah satunya adalah dengan mengurangi kandungan kadar air pada biji mentah. Sesuai dengan standar mutu kopi kering itu sendiri adalah sekitar $12,5 \%$, kondisi kadar air seperti ini kopi masih tergolong keras untuk proses penghancuran biji kopi dan juga tidak sesuai dengan standar kopi bubuk itu sendiri. Sehingga di butuhkan penurunan kadar air lanjutan untuk pengolahan kopi yang dilakukan dengan pemanas kembali pada kopi. Proses penurunan kadar air ini, biasanya di hentikan dengan cara memprediksi dari warna pada biji kopi yang telah terlihat hitam pekat.

Atas dasar tersebut penulis membuat Pengontrolan Suhu pada Sangrai Biji maka perlu Kopi, Alat ini akan melakukan penyangraian kopi menggunakan sensor thermocouple untuk mengukur suhu tabung yang berasal dari heater. Alat ini akan berhenti beroperasi ketika terlihat warna biji kopi telah berwarna hitam dan muda hancur. Cara pemantauan warna biji kopi ini akan dilakukan dengan cara mengambil beberapa contoh biji kopi yang sedang di sangrai melalui pengontrolan outputan atau pintu keluar pada biji kopi.

\section{Tanaman Kopi}

Kopi merupakan salah satu jenis tanaman perkebunan yang sudah lama dibudidayakan dan memiliki nilai ekonomis yang lumayan tinggi. Konsumsi kopi dunia mencapai $70 \%$ berasal dari spesies kopi arabika dan $26 \%$ berasal dari spesies kopi robusta. Kopi berasal dari Afrika, yaitu daerah pegunungan di Etopia. Namun, kopi sendiri baru dikenal oleh masyarakat dunia setelah tanaman tersebut dikembangkan di 
luar daerah asalnya, yaitu Yaman di bagian selatan Arab, melalui para saudagar Arab (Rahardjo, 2012).

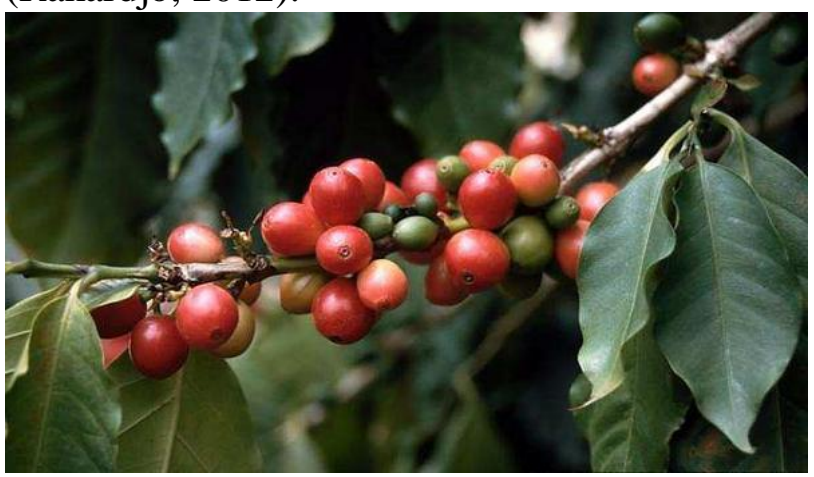

Gambar 1. Buah Kopi

Di Indonesia kopi mulai di kenal pada tahun 1696, yang di bawa oleh VOC. Tanaman kopi di Indonesia mulai di produksi di pulau Jawa, dan hanya bersifat coba-coba, tetapi karena hasilnya memuaskan dan dipandang oleh VOC cukup menguntungkan sebagai komoditi perdagangan maka VOC menyebarkannya ke berbagai daerah agar para penduduk menanamnya (Najiyanti dan Danarti, 2004).

Kopi (Coffea sp.) adalah spesies tanaman berbentuk pohon. Tanaman ini tumbuh tegak, bercabang dan bila dibiarkan akan mencapai tinggi12 meter. Tanaman ini memiliki beberapa jenis cabang yaitu cabang reproduksi, cabang primer dan cabang sekunder, cabang kipas, cabang perut, cabang balik dan cabang air. Kopi merupakan sumber kafein. Kafein banyak memiliki manfaat dan telah banyak digunakan dalam dunia medis. Kafein dapat dibuat dari ekstrak kopi, teh dan cokelat. Kafein berfungsi untuk merangsang aktivitas susunan saraf dan meningkatkan kerja jantung, sehingga jika dikonsumsi dalam jumlah berlebihan akan bersifat racun dengan menghambat mekanisme susunan saraf manusia (Mumin, 2006). Menurut Najiyanti (2001), adapun klasifikasi tanaman kopi adalah sebagai berikut: Kingdom : Plantae Divisi : Spermatophyta, Subdivisio : Angiospermae, Kelas : Dycotiledoneae, Ordo : Rubiales, Famili : Rubiaceae, Genus : Coffea, Spesies : Coffea sp.

\section{Kopi Robusta}

Di dunia perdagangan dikenal beberapa golongan kopi, tetapi yang paling sering dibudidayakan hanya kopi arabika, robusta, dan liberika. Pada umumnya, penggolongan kopi berdasarkan spesies, kecuali kopi robusta. Kopi robusta bukan nama spesies karena kopi ini merupakan keturunan dari berapa spesies kopi terutama Coffea canephora (Najiyati dan Danarti, 2004).

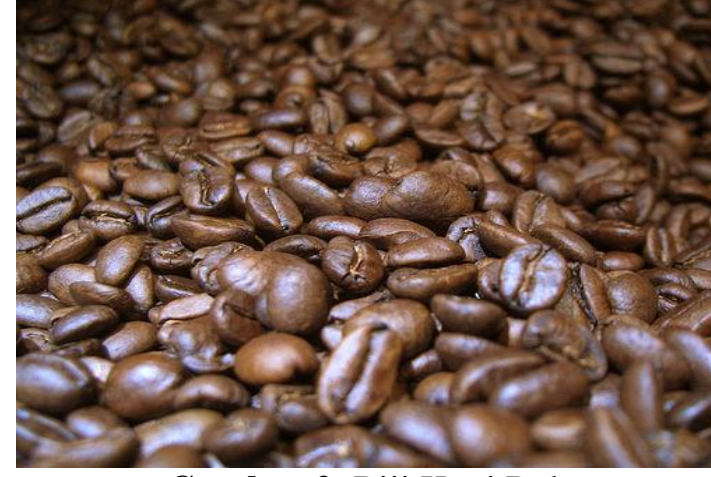

Gambar 2. Biji Kopi Robusta

Sistematika tanaman kopi robusta menurut Rahardjo, (2012) adalah sebagai berikut:

Kingdom : Plantae, Sub kingdom : Tracheobionita, Divisi : Magnoliophyta, Kelas : Magnoliopsida Sub Kelas : Astridae , Ordo : Rubiaceace, Genus : Coffea Spesies : Coffea robusta

Kopi robusta memiliki tekstur lebih kasar dari kopi arabika. Jenis lainnya dari kopi robusta seperti Qillou, Uganda dan Chanepora. Dalam pertumbuhannya kopi robusta hampir sama dengan kopi arabika yakni tergantung pada kondisi tanah, cuaca, proses pengolahan. Pengemasan kopi ini akan berbeda untuk setiap negara dan menghasilkan rasa yang sedikit banyak juga berbeda. Kopi robusta biasanya digunakan sebagai kopi instant atau cepat saji. Kopi robusta memiliki kandungan kafein yang lebih tinggi, rasanya lebih netral, serta aroma kopi yang lebih kuat. Kandungan kafein pada kopi robusta mencapai 2,8\% serta memiliki jumlah kromosom sebanyak 22 kromosom. (Anonim, 2012a).

\section{Proses Pengolahan Bubuk Kopi}

Proses ini merupakan tahapan pembentukan aroma dan citarasa khas kopi dari dalam biji kopi dengan perlakuan panas. Biji kopi 
secara alami mengandung cukup banyak senyawa organik calon pembentuk citarasa dan aroma khas kopi. Makin lama waktu sangrai, warna biji kopi sangrai mendekati cokelat tua kehitaman (Mulato, 2002). Berdasarkan suhu penyangraian yang digunakan kopi sangrai dibedakan atas 3 golongan yaitu ligh roast suhu yang digunakan $193{ }^{\circ} \mathrm{C}$ sampai $199{ }^{\circ} \mathrm{C}$, medium roast suhu yang digunakan $204{ }^{\circ} \mathrm{C}$ dan dark roast suhu yang digunakan $213{ }^{\circ} \mathrm{C}$ sampai $221{ }^{\circ} \mathrm{C}$. Light roast menghilangkan 3-5\% kadar air, medium roast menghilangkan 5$8 \%$ dan 10 dark roast menghilangkan 814\% kadar air (Varnam and Sutherland, 1994).

Pada proses penyangraian kopi mengalami perubahan warna dari hijau atau cokelat muda menjadi cokelat kayu manis, kemudian menjadi hitam dengan permukaan berminyak. Bila kopi sudah berwarna hitam dan mudah pecah (retak) maka penyangraian segera dihentikan. Selanjutnya kopi segera diangkat dan didinginkan.

\section{Sensor}

D Sharon, dkk (1982), mengatakan sensor adalah suatu peralatan yang berfungsi untuk mendeteksi gejala-gejala atau sinyal-sinyal yang berasal dari perubahan suatu energi seperti energi listrik, energi fisika, energi kimia, energi biologi, energi mekanik dan sebagainya. Dalam memilih peralatan sensor dan transduser yang tepat dan sesuai dengan sistem yang akan disensor maka perlu diperhatikan persyaratan umum sensor berikut ini : (D Sharon, dkk, 1982)

\section{A. linieritas}

Ada banyak sensor yang menghasilkan sinyal keluaran yang berubah secara kontinyu sebagai tanggapan terhadap masukan yang berubah secara kontinyu. Sebagai contoh, sebuah sensor panas dapat menghasilkan tegangan sesuai dengan panas yang dirasakannya. Salah satu metoda linieritas yaitu linierisasi regresi. Linierisasi regresi atau dikenal dengan least-squares linierity, secara umum dapat ditulis

\section{B. Sensitivitas}

Sensitivitas akan menunjukan seberapa jauh kepekaan sensor terhadap kuantitas yang diukur. Sensitivitas sering juga dinyatakan dengan bilangan yang menunjukan "perubahan keluaran dibandingkan unit perubahan masukan"untuk elemen ideal $(\mathrm{DO} / \mathrm{DI}=\mathrm{K})$. Beberepa sensor panas dapat memiliki kepekaan yang dinyatakan dengan "satu volt per derajat", yang berarti perubahan satu derajat pada masukan akan menghasilkan perubahan satu volt pada keluarannya. Sensor panas lainnya dapat saja memiliki kepekaan "dua volt per derajat", yang berarti memiliki kepakaan dua kali dari sensor yang pertama. Linieritas sensor juga mempengaruhi sensitivitas dari sensor. Apabila tanggapannya linier, maka sensitivitasnya juga akan sama untuk jangkauan pengukuran keseluruhan.

\section{Tanggapan Waktu}

Tanggapan waktu pada sensor menunjukan seberapa cepat tanggapannya terhadap perubahan masukan Ada bermacam cara untuk menyatakan tanggapan frekuensi sebuah sensor. Misalnya "satu milivolt pada 500 hertz". Tanggapan frekuensi dapat pula dinyatakan dengan "decibel (db)", yaitu untuk membandingkan daya keluaran pada frekuensi tertentu dengan daya keluaran pada frekuensi referensi.

\section{Sensor Termocouple}

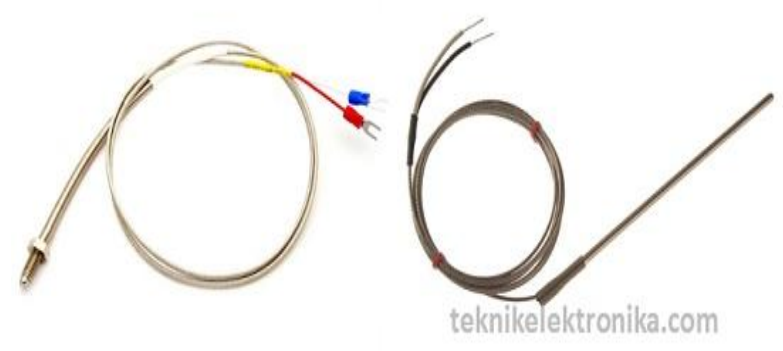

Gambar 3. Termocouple

Pembuatan termokopel didasarkan atas sifat thermal bahan logam. Jika sebuah 
batang logam dipanaskan pada salah satu ujungnya maka pada ujung tersebut elektron-elektron dalam logam akan bergerak semakin aktif dan akan menempati ruang yang semakin luas, elektron-elektron saling desak dan bergerak ke arah ujung batang yang tidak dipanaskan. Dengan demikian pada ujung batang yang dipanaskan akan terjadi muatan positif. Kerapatan electron untuk setiap bahan logam berbeda tergantung dari jenis logam. Jika dua batang logam disatukan salah satu ujungnya, dan kemudian dipanaskan, maka elektron dari batang logam yang memiliki kepadatan tinggi akan bergerak ke batang yang kepadatan elektronnya rendah, dengan demikian terjadilah perbedaan tegangan diantara ujung kedua batang logam yang tidak disatukan atau dipanaskan. Besarnya termolistrik atau gem ( gaya electromagnet ) yang dihasilkan menurut T.J Seeback (1821) yang menemukan hubungan perbedaan panas $\left(T_{1}\right.$ dan $\left.T_{2}\right)$ dengan gaya gerak listrik yang dihasilkan $E$, Peltir (1834), menemukan gejala panas yang mengalir dan panas yang diserap pada titik hot-juction dan cold-junction, dan Sir William Thomson, menemukan arah arus mengalir dari titik panas ke titik dingin dan sebaliknya

Prinsip kerja Termokopel cukup mudah dan sederhana. Pada dasarnya Termokopel hanya terdiri dari dua kawat logam konduktor yang berbeda jenis dan digabungkan ujungnya. Satu jenis logam konduktor yang terdapat pada Termokopel akan berfungsi sebagai referensi dengan suhu konstan (tetap) sedangkan yang satunya lagi sebagai logam konduktor yang mendeteksi suhu panas.

Termokopel(Thermocouple)

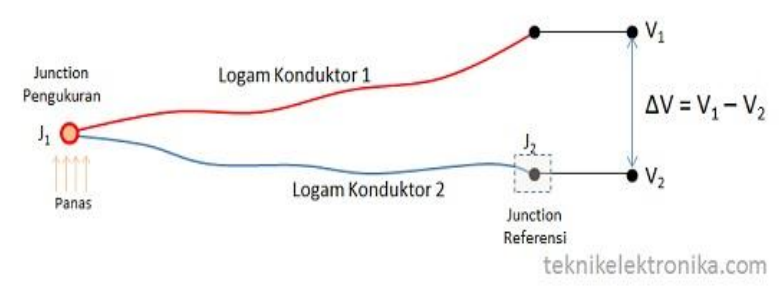

Gambar 4. Prinsip Kerja Termocouple
Berdasarkan Gambar prinsip kerja termocouple, ketika kedua persimpangan atau Junction memiliki suhu yang sama, maka beda potensial atau tegangan listrik yang melalui dua persimpangan tersebut adalah "NOL" atau V1 = V2. Akan tetapi, ketika persimpangan yang terhubung dalam rangkaian diberikan suhu panas atau dihubungkan ke obyek pengukuran, maka akan terjadi perbedaan suhu diantara dua persimpangan tersebut yang kemudian menghasilkan tegangan listrik yang nilainya sebanding dengan suhu panas yang diterimanya atau V1 - V2. Tegangan Listrik yang ditimbulkan ini pada umumnya sekitar $1 \mu \mathrm{V}-70 \mu \mathrm{V}$ pada tiap derajat Celcius. Tegangan tersebut kemudian dikonversikan sesuai dengan Tabel referensi yang telah ditetapkan sehingga menghasilkan pengukuran.

Table 1. Tipe Termocouple

\begin{tabular}{|c|l|c|}
\hline $\begin{array}{c}\text { Code } \\
\text { Type }\end{array}$ & \multicolumn{1}{|c|}{ Conductors (+/-) } & Sensitivity \\
\hline $\mathbf{E}$ & $\begin{array}{l}\text { Nickel Chromium / } \\
\text { Constantan }\end{array}$ & $\begin{array}{c}-200 \text { to } 900 \\
{ }^{\circ} \mathrm{C}\end{array}$ \\
\hline $\mathbf{J}$ & Iron / Constantan & 0 to $750{ }^{\circ} \mathrm{C}$ \\
\hline $\mathbf{K}$ & $\begin{array}{l}\text { Nickel Chromium / } \\
\text { Nickel Aluminium }\end{array}$ & $\begin{array}{c}-200 \text { to } \\
1250{ }^{\circ} \mathrm{C}\end{array}$ \\
\hline $\mathbf{N}$ & Nicrosil / Nisil & $\begin{array}{c}0 \text { to } 1250 \\
{ }^{\circ} \mathrm{C}\end{array}$ \\
\hline $\mathbf{T}$ & Copper / Constantan & $\begin{array}{c}-200 \text { to } 350 \\
{ }^{\circ} \mathrm{C}\end{array}$ \\
\hline $\mathbf{U}$ & $\begin{array}{l}\text { Copper / Copper } \\
\text { Nickel Compensating } \\
\text { for "S" and "R" }\end{array}$ & $\begin{array}{c}0 \text { to } 1450 \\
{ }^{\circ} \mathrm{C}\end{array}$ \\
\hline
\end{tabular}

\section{Mikrokontroler}

Mikrokontroler adalah sebuah sistem komputer fungsional dalam sebuah chip. Di dalamnya terkandung sebuah inti prosesor, memori (sejumlah kecil RAM, memori program, atau keduanya), dan perlengkapan input output. Dengan kata lain, mikrokontroler adalah suatu alat elektronika digital yang mempunyai masukan dan keluaran serta kendali dengan program yang bisa ditulis dan dihapus dengan cara khusus, cara kerja 
mikrokontroler sebenarnya membaca dan menulis data.

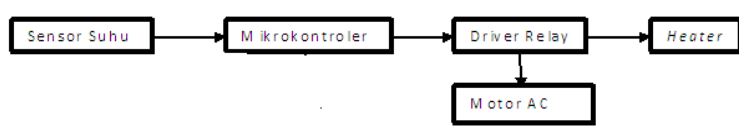

Gambar 5. Blok Diagram Fungsi Sensor Suhu

Sensor suhu ini mempunyai 5 pin yang mempunyai fungsi yang berbeda. Pin 1 yaitu GND yang akan di hubungkan pada pada GND, pin 2 yaitu Vcc yang akan di hubungkan pada pin $5 \mathrm{~V}$, pin ke 3 yaitu SCK yang di hubungkan pada pin digital 6 (D6), pin ke 4 yaitu CS yang dihubungkan pada pin digital 5(A5), dan pin ke 5 yaitu SO yang dihubungkan pada pin digital $5(\mathrm{~A} 4)$

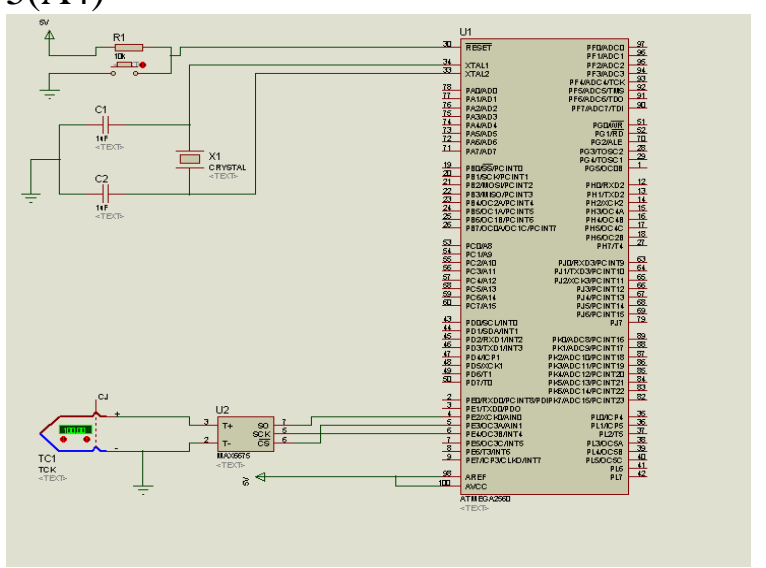

Gambar 6. Rangkaian Sensor Suhu Thermocoupel

Tabel 2. Koneksi Pin dari Sensor Suhu ke Pin Mikrokontroler Arduino

\begin{tabular}{|c|c|c|}
\hline $\begin{array}{c}\text { Pin Pada } \\
\text { Sensor } \\
\text { Suhu }\end{array}$ & Keterangan & $\begin{array}{c}\text { Terhubung } \\
\text { Ke }\end{array}$ \\
\hline Pin 1 & Vcc +5V & Vcc +5V \\
\hline Pin 2 & Ground & Ground \\
\hline Pin 3 & Pin Data CLK & $\begin{array}{c}\text { Pin Digital } \\
\text { D6 }\end{array}$ \\
\hline Pin 4 & Pin Data CS & $\begin{array}{c}\text { Pin Digital } \\
\text { D5 }\end{array}$ \\
\hline Pin 5 & Pin Data SO & $\begin{array}{c}\text { Pin Digital } \\
\text { D4 }\end{array}$ \\
\hline
\end{tabular}

\section{Rangkaian Driver Relay}

Rangkaian driver ini digunakan mengaktifkan dan menonatifkan heater serta motor AC. Sehingga heater tidak akan selalu hidup untuk memanaskan tabung pemanas dan dapat mengontrol aktifnya motor ac. Pada dasarnya rangkaian ini akan aktif ketika arduino memberikan data berupa output tegangan dari pin yang terhubung ke rangkaian relay. Lalu tegangan ini akan masuk ke relay yang akan memicu pergerakan pada magnet yang terdapat di dalam relay itu sendiri. Ketika magnet tersebut telah bergeser maka heater dan motor ac akan aktif. Untuk input tegangan relay ini sendiri membutuhkan tegangan sebesar 5VDC.

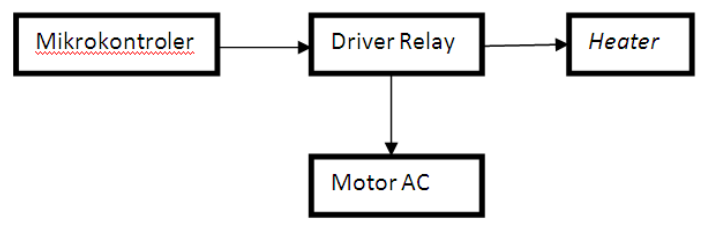

Gambar 7. Blok Diagram Rangkaian Relay Arduino

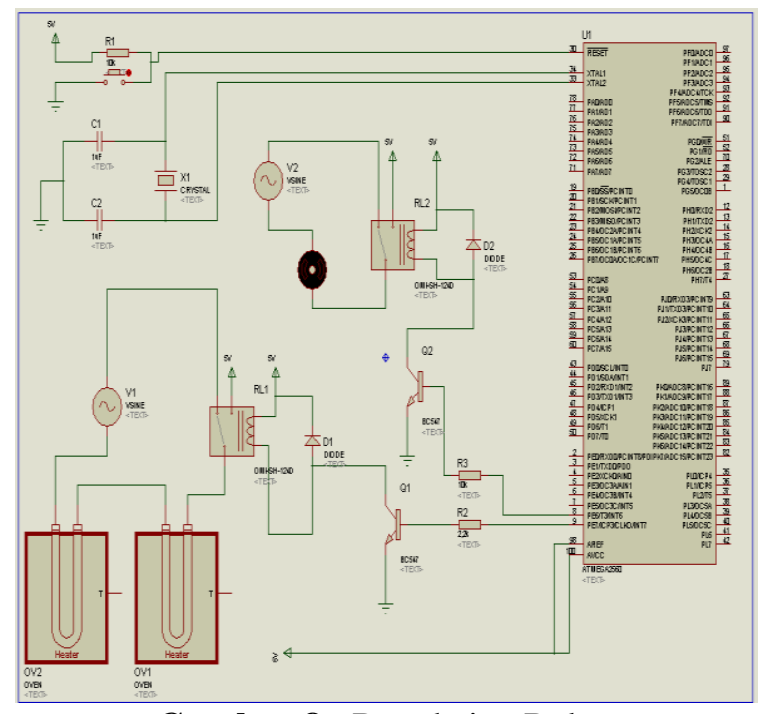

Gambar 8. Rangkaian Relay

\section{Rangkaian Motor Servo}

Rangkaian Motor servo ini akan di gunakan untuk membuka dan menutup pintu untuk keluarnya biji kopi. Pada motor servo pengontrolan yang di lakukan dengan sudut putaran, sehingga sangat memudahkan untuk di aplikasikan sebagai pembuka pintu. Sudut putaran motor servo ini $0^{0}-180^{\circ}$. Sementara pada alat ini akan di 
lakukan pengontrolan pada sudut $90^{\circ}$. Pengontrolan ini akan dilakukan oleh software labview.

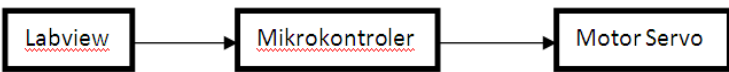

Gambar 9. Blok diagram Motor Servo

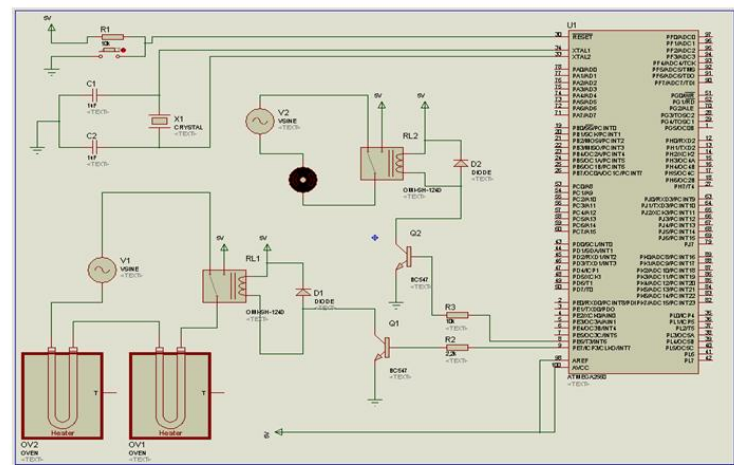

Gambar 10. Rangkaian Motor Servo ke Mikrokontroler Arduino

Tabel 3. Hubungan Rangkaian Motor Servo ke Pin Arduino

\begin{tabular}{|c|c|c|}
\hline $\begin{array}{c}\text { Pin Pada } \\
\text { Sensor } \\
\text { Kelembapan }\end{array}$ & Keterangan & $\begin{array}{c}\text { Terhubung } \\
\text { Ke }\end{array}$ \\
\hline Pin 1 & Data & $\begin{array}{c}\text { Pin Digital } \\
\text { D7 }\end{array}$ \\
\hline Pin 2 & Vcc & 5VDC \\
\hline Pin 3 & GND & GND \\
\hline
\end{tabular}

\section{METODOLOGI}

\section{Perancangan Software}

Pada alat ini menggunakan dua buah software, yaitu menggunakan software arduino dan software labview yang akan saling berinteraksi.

\section{Perancangan Software Arduino}

Software ini akan di gunakan untuk mengontrol Arduino mega 2560 serta untuk mengola data input dan output, dan juga untuk membuka komunikasi antara labview dan arduino.

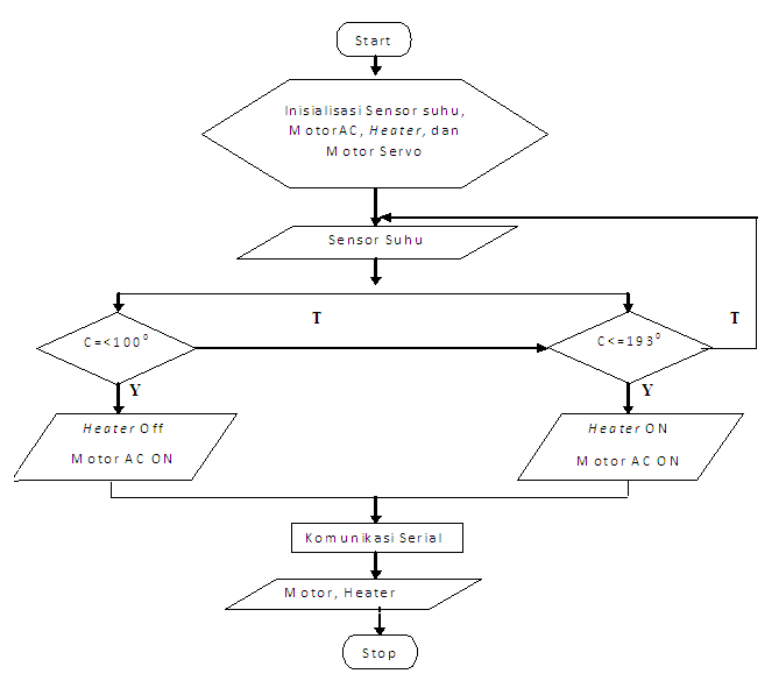

Gambar 11. Flowchart kontrol Software Arduino

\section{HASIL DAN PEMBAHASAN}

\section{Pengujian Rangkaian Relay}

Pengujian pada rangkaian relay ini di lakukan dengan tujuan untuk mengetahui kinerja pada rangkaian dan tegangan output yang di hasilkan dari data arduino, data input sumber, tegangan pada basis, tegangan pada kolektor dan tegangan keluaran dari relay, sehingga rangkaian relay ini akan di fungsikan sebagai Kontrol on off pada sebuah objek. Cara pengujian yang akan di lakukan dengan cara mengaktifkan rangkaian dan menonaktif kan rangkaian. Ketika rangkaian berada dalam kondisi aktif atau tidak, akan di ukur tegangan pada setiap titik yang telah di lampirkan pada gambar titik pengukuran di bawah ini:

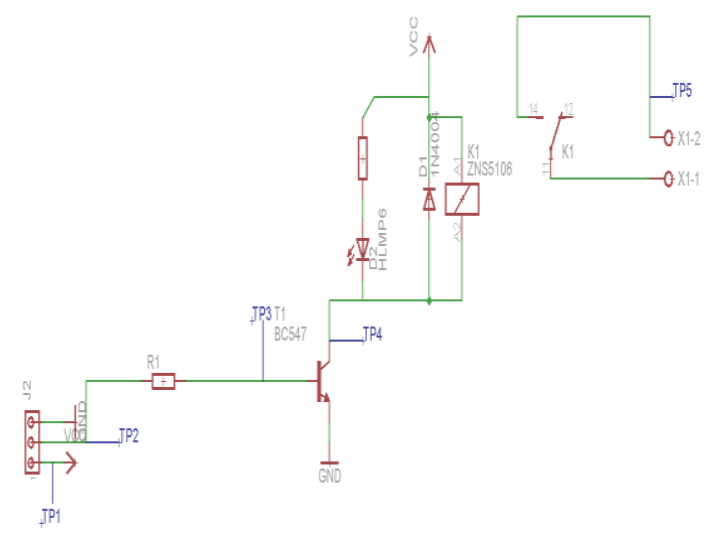

Gambar 12. Titik Pengukuran 
Tabel 4. Pengukuran Lebar Pulsa

\begin{tabular}{|l|l|l|}
\hline Kondisi Pintu & $\begin{array}{l}\text { Sudut Motor } \\
\text { Servo }\end{array}$ & Lebar Pulsa \\
\hline Tertutup & $0^{0}$ & $0,4 \mathrm{~ms}$ \\
\hline Terbuka & $90^{\circ}$ & $1,5 \mathrm{~ms}$ \\
\hline
\end{tabular}

Pada hasil pengukuran yang telah di lakukan dapat di ketahui, rangkaian ini akan aktif ketika di berikan tegangan dari arduino. Sesuai pengukuran hasil tegangan pada arduino sebesar 4,87V. Hasil ini mendekati dari karakteristik output pada arduino yaitu sebesar 5V. Ketika di berikan tegangan pada arduino, tegangan akan masuk ke transistor yang bekerja sebagai saklar pada rangkaian ini. Sehingga peran transistor sangat di butuhkan untuk mengontrol tegangan. Terdapat dua buah kondisi transistor ini, yaitu kondisi saturasi (saklar on) dan kondisi cut off (saklar Off). Kondisi saturasi ini akan di dapatkan ketika tegangan yang melalui VBE lebih besar dari $0,7 \mathrm{~V}$. Sedangkan tegangan yang terukur pada VBE yaitu $0,83 \mathrm{~V}$, dan $\mathrm{VCE}=0 \mathrm{~V}$ sedangkan pengukuran pada VCE adalah $0,05 \mathrm{~V}$, sehingga pada rangkaian ini transistor berada pada posisi saturasi yang berarti saklar on. Dan tegangan akan terhubung ke relay, karna tegangan yang masuk ini akan mengakibatkanya terjadi penarikan kumparan magnet pada relay, sehingga relay berada pada kondisi on. Rangkaian relay ini berada dalam kondisi off ketika tidak ada tegangan input dari arduino, sehingga tidak ada tegangan yang akan masuk ke dalam basis transistor. Sehingga transistor sebagai relay akan off atau berada dalam kondisi cut off. Kondisi cut off ini dapat terjadi apabila tegangan pada VBE lebih kecil dari 0,7V dan tegangan VCE sama dengan tegangan referensi atau tegangan sumber. Dari hasil data pengujian, dapat di ketahui tegangan pada VBE 0V yang berarti lebih kecil dari $0,7 \mathrm{~V}$ sedangkan tegangan pada VCE adalah $4,95 \mathrm{~V}$ sama dengan tegangan sumber. Sehingga transistor berada pada kondisi cut off yang berarti saklar dalam kondisi off yang mengakibatkan tegangan tidak dapat mengalir ke relay, sehingga relay berada dalam kondisi off.

\section{Pengujian Motor servo}

Pengujian pada motor servo ini di lakukan untuk mengetahui data keluaran yang akan di hasilkan dari pengontrolan posisi sudut motor servo. Pengontrolan posisi sudut derajat motor servo ini dikendalikan melalui lebar pulsa, sehingga pengukuran di lakukan pada kabel data motor servo yang terhubung langsung ke pada osiloskop dan akan melihat respon lebar pulsa yang akan di berikan dari kabel data motor servo. Pengukuran di lakukan sesuai dengan kegunaan motor servo yang akan di gerakan $0^{0}$ saat pintu tertutup dan $90^{\circ}$ saat pintu terbuka.

Tabel 5. Pengukuran Lebar Pulsa

\begin{tabular}{|l|l|l|}
\hline $\begin{array}{l}\text { Kondisi } \\
\text { Pintu }\end{array}$ & $\begin{array}{l}\text { Sudut Motor } \\
\text { Servo }\end{array}$ & $\begin{array}{l}\text { Lebar } \\
\text { Pulsa }\end{array}$ \\
\hline Tertutup & $0^{0}$ & $0,4 \mathrm{~ms}$ \\
\hline Terbuka & $90^{\circ}$ & $1,5 \mathrm{~ms}$ \\
\hline
\end{tabular}

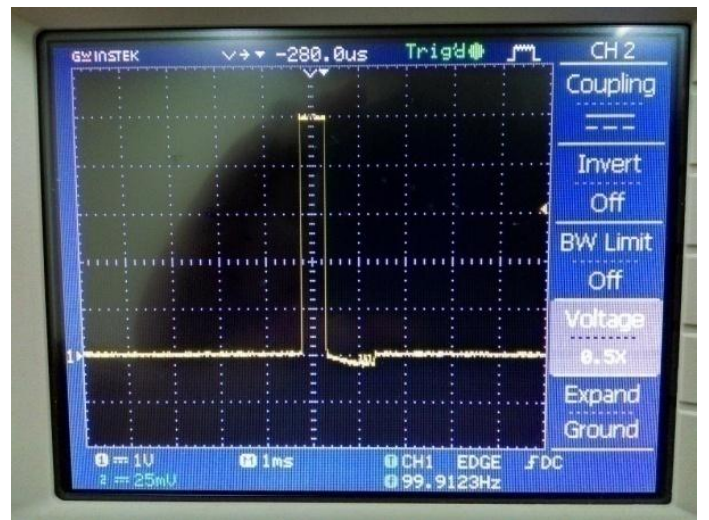

Gambar 13. Lebar Pulsa 0,4 ms Posisi Sudut Motor Servo $0^{0}$

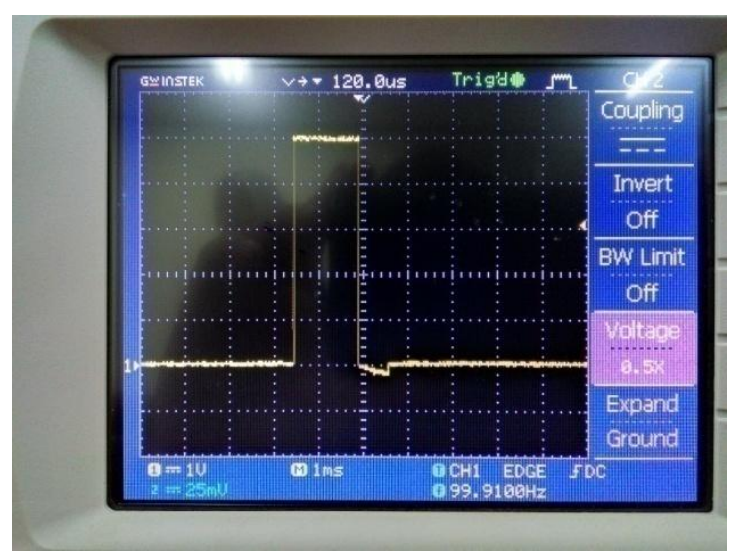

Gambar 14. Lebar Pulsa 1,5 ms 
Posisi Sudut Motor Servo 90 ${ }^{0}$

Pengukuran yang di lakukan ini di lakukan dengan secara langsung memberikan pergerakan motor yang langsung di instruksi kan oleh labview. Dari hasil pengukuran yang telah di lakukan, dapat di ketahui bahwa motor servo bergerak berdasarkan lebar pulsa. Dimana secara teoritis, ketika motor berada pada posisi $90^{\circ}$ maka lebar pulsa yang akan terbaca adalah $1,5 \mathrm{~ms}$. Sedangkan pada proses pengukuran terlihat bahwa lebar pulsa $1,5 \mathrm{~ms}$ saat motor servo berada pada sudut $90^{\circ}$. sehingga hasil pada pergerakan sudut $90^{\circ}$ yang di kontrol langsung oleh labview ini benar benar berada pada posisi $90^{0}$ karena memiliki lebar pulsa yang sama yaitu $1,5 \mathrm{~ms}$

\section{Pengujian Sensor Suhu}

Sensor suhu akan di fungsikan untuk membaca besaran suhu setiap kali kenaikan dan penurunan panas yang akan di timbulkan, sehingga sensor ini akan sangat berperan penting untuk alat sangrai yang dirancang. Oleh karena perannya sebagai pendeteksi besaran suhu di sebuah ruangan, maka sangat di butuhkan pengujian untuk pembacaan sensor suhu. Pengujian sensor suhu ini dilakukan untuk mengetahui pembacaan besaran suhu setiap kali kenaikan dan penurunan suhu yang di timbulkan oleh pemanas (heater). Cara pengujian sensor ini di lakukan dengan membandingkan hasil besaran suhu pada sensor dengan besaran suhu pada alat ukur suhu berupa thermometer. Dari hasil perbandingan ini, akan dapat dilihat apakah sensor yang di gunakan dapat menghasilkan besaran suhu yang sebenarnya. Selain membandingkan data dilakukan juga pengukuran pada tegangan output thermocouple. Pengukuran tengangan output ini di lakukan untuk melihat besaran output tegangan setiap kali kenaikan suhu.
Tabel 6. Pengujian Data Suhu

\begin{tabular}{|c|c|c|c|c|}
\hline \multirow{2}{*}{$\begin{array}{l}\mathrm{N} \\
\mathrm{O}\end{array}$} & \multicolumn{2}{|c|}{ Suhu } & \multirow{2}{*}{$\begin{array}{l}\text { Erro } \\
\text { r(\%) } \\
\text { Data } \\
\text { Suhu }\end{array}$} & \multirow{2}{*}{$\begin{array}{c}\text { Tegangan } \\
\text { Output } \\
\text { Thermocou } \\
\text { ple }(\mathrm{mV})\end{array}$} \\
\hline & $\begin{array}{c}\text { Therm } \\
\text { ocoupl } \\
\mathrm{e}\end{array}$ & $\begin{array}{l}\text { Therm } \\
\text { ometer }\end{array}$ & & \\
\hline 1 & $31^{0} \mathrm{C}$ & $32^{0} \mathrm{C}$ & 1 & 0 \\
\hline 2 & $35^{\circ} \mathrm{C}$ & $34^{0} \mathrm{C}$ & 1 & 0,2 \\
\hline 3 & $40^{\circ} \mathrm{C}$ & $39^{0} \mathrm{C}$ & 1 & 0,5 \\
\hline 4 & $45^{0} \mathrm{C}$ & $44^{0} \mathrm{C}$ & 1 & 0,8 \\
\hline 5 & $50^{\circ} \mathrm{C}$ & $50^{\circ} \mathrm{C}$ & 0 & 1,2 \\
\hline 6 & $55^{0} \mathrm{C}$ & $55^{0} \mathrm{C}$ & 0 & 1,4 \\
\hline 7 & $60^{\circ} \mathrm{C}$ & $59^{0} \mathrm{C}$ & 1 & 1,7 \\
\hline 8 & $65^{0} \mathrm{C}$ & $65^{0} \mathrm{C}$ & 0 & 2 \\
\hline 9 & $70^{\circ} \mathrm{C}$ & $70^{\circ} \mathrm{C}$ & 0 & 2,3 \\
\hline 10 & $75^{\circ} \mathrm{C}$ & $75^{\circ} \mathrm{C}$ & 0 & 2,5 \\
\hline 11 & $80^{\circ} \mathrm{C}$ & $79^{0} \mathrm{C}$ & 1 & 2,8 \\
\hline 12 & $85^{\circ} \mathrm{C}$ & $84^{0} \mathrm{C}$ & 1 & 3 \\
\hline 13 & $90^{\circ} \mathrm{C}$ & $90^{\circ} \mathrm{C}$ & 0 & 3,3 \\
\hline 14 & $95^{\circ} \mathrm{C}$ & $95^{\circ} \mathrm{C}$ & 0 & 3,6 \\
\hline 15 & $100^{0} \mathrm{C}$ & $99^{0} \mathrm{C}$ & 1 & 3,8 \\
\hline 16 & $110^{\circ} \mathrm{C}$ & $109^{0} \mathrm{C}$ & 1 & 4,3 \\
\hline 17 & $120^{\circ} \mathrm{C}$ & $120^{\circ} \mathrm{C}$ & 0 & 4,8 \\
\hline 18 & $130^{\circ} \mathrm{C}$ & $130^{\circ} \mathrm{C}$ & 0 & 5,4 \\
\hline 19 & $140^{\circ} \mathrm{C}$ & $140^{\circ} \mathrm{C}$ & 0 & 5,9 \\
\hline 20 & $150^{\circ} \mathrm{C}$ & $149^{0} \mathrm{C}$ & 1 & 6,3 \\
\hline 21 & $160^{\circ} \mathrm{C}$ & $159^{\circ} \mathrm{C}$ & 1 & 6,8 \\
\hline 22 & $170^{\circ} \mathrm{C}$ & $170^{\circ} \mathrm{C}$ & 0 & 7,2 \\
\hline 23 & $180^{\circ} \mathrm{C}$ & $180^{\circ} \mathrm{C}$ & 0 & 7,7 \\
\hline 24 & $190^{\circ} \mathrm{C}$ & $190^{\circ} \mathrm{C}$ & 0 & 8,2 \\
\hline 25 & $200^{0} \mathrm{C}$ & $200^{0} \mathrm{C}$ & 0 & 8,7 \\
\hline \multicolumn{3}{|c|}{ Jumlah Eror } & 11 & \\
\hline \multicolumn{3}{|c|}{ Eror rata-rata } & 0,44 & \\
\hline
\end{tabular}


Tabel 7. Pengaruh suhu terhadap kadar air

\begin{tabular}{|l|l|}
\hline $\begin{array}{l}\text { Suhu } \\
(0 C)\end{array}$ & $\begin{array}{l}\% \\
\text { pengurangan } \\
\text { kadar air }\end{array}$ \\
\hline T1 (190) & 3.36 \\
\hline T2 (193) & 5.45 \\
\hline T3(199) & 5.59 \\
\hline T4 (200) & 6.22 \\
\hline T5 (204) & 6.80 \\
\hline T6 (213) & 7.22 \\
\hline T7 (217) & 7.79 \\
\hline T8(220) & 8.10 \\
\hline T9(223) & 8.20 \\
\hline
\end{tabular}

Perhitungan kadar air dengan menggunaka teori Brooker et al [10], Persamaan dalam penentuan kadar air kering (dry basis) berlaku rumus:

$$
\mathrm{MC}_{\mathrm{d} . \mathrm{b}}=\frac{100 \mathrm{MCwb}}{100-\mathrm{MCwb}} \text { atau } \frac{\mathrm{Wa}-\mathrm{Wb}}{\mathrm{Wb}}
$$

Tahapan yang dilakukan pada pengukuran, dengan suhu , $190{ }^{\circ} \mathrm{C}-214{ }^{\circ} \mathrm{C}$ dan menggunakan biji kopi arabika kering, dengan waktu 15 sampai 20 menit, kehilangan berat kering terkait erat dengan suhu penyangraian. Suhu penyangraian yang digunakan kopi sangrai dibedakan atas 3 golongan yaitu ligh roast suhu yang digunakan $193^{\circ} \mathrm{C}$ sampai $199^{\circ} \mathrm{C}$, medium roast suhu yang digunakan $204^{\circ} \mathrm{C}$ dan dark roast suhu yang digunakan $213^{\circ} \mathrm{C}$ sampai $221^{\circ} \mathrm{C}$.

Dari pengujian pengujian Kadar air biji kopi setelah penyangraian cenderung menurun dengan meningkatnya suhu dan lama penyangraian, Dimana pada suhu $193^{\circ} \mathrm{C}$ dan $199{ }^{\circ} \mathrm{C}$ (ligh roast) didapatkan rata-rata kadar air $5.47 \%$, pada suhu $104^{\circ} \mathrm{C}$ (medium roast) didapatkan rata-rata kadar air $6.80 \%$ dan $213^{\circ} \mathrm{C}-220^{\circ} \mathrm{C}$ (dark roast) didapatkan rata-rata kadar air $7.70 \%$. Ligh roast menghilangkan 3-5\% kadar air: medium roast, 5-8 \% dan dark roast $8-14 \%$ ((Varnam and Sutherland, 1994)

\section{SIMPULAN}

Suhu penyangraian sangat berpengaruh terhadap kadar air biji kopi dimana pengurangan kadar air pada suhu $193^{\circ} \mathrm{C}$ dan $199{ }^{\circ} \mathrm{C}$ (ligh roast) didapatkan rata-rata kadar air $5.47 \%$, pada suhu $104^{\circ} \mathrm{C}$ (medium roast) didapatkan rata-rata kadar air $6.80 \%$ dan $213^{\circ} \mathrm{C}-220^{\circ} \mathrm{C}$ (dark roast) didapatkan rata-rata kadar air $7.70 \%$.

\section{DAFTAR PUSTAKA}

[1] Ditjenbun, 2012. Perbaikan Mutu Kopi Indonesia. Direktorat Jenderal Perkebunan. Departemen Pertanian.

[2] Rahardian, D., 2011. Proses Pengolahan Biji Kopi. Jurusan Ilmu Teknologi Pangan Universitas Sebelas Maret. Diakses 5 Oktober 2012.

[3] Lestari, Dewi. 2006. Analisis dan Implementasi Penghalusan Citra (Image Smoothing) pada Citra Digital Menggunakan Metode Uniform Smoothing, Gaussian Smoothing, dan Threshold Smoothing. Skripsi. Bandung. UNIKOM.

[4] tandar Nasional Indonesia. SNI 012907- 2008. Biji Kopi. Badan Standardisasi Nasional [5] Prihatini, Tuti Adi. 2011. Analisis Dan Implementasi Low Pass Filter Untuk Mereduksi Noise Pada Citra Digital. Skripsi. Medan. Universitas Sumatera Utara.

[5] Oka, A.A dan Joko, N.W.K; 2010. Aplikasi Elektronic Nose Pada Penentuan Kematangan Buah Sawo(Manilkara Achras) menggunakan Sistem Pengenalan Pola Jaringan Syaraf Tiruan. Perpustakaan FTP UGM. Yogyakarta

[6] Sumarlin, 2007. Upaya Peningkatan Mutu Biji Kopi. http://disbunlambar. wordpress.com/2007/10/30/mutu- 
biji-kopi-lampung barat/. Diakses

9 Oktober 2012

[7] Siswoputranto,P.S, Kopi Internasional dan Indonesia, Yogyakarta: Kanisius, 1993.

[8] Varnam, H.A. and Sutherland, J. P. 1994. Beverages (Technology, Chemestry and Microbiology). Chapman and Hall, London

[9] Mulato, Sri. 2002. Simposium Kopi 2002 dengan tema Mewujudkan perkopian Nasional Yang Tangguh melalui Diversifikasi Usaha Berwawasan Lingkungan dalam Pengembangan Industri Kopi Bubuk Skala Kecil Untuk Meningkatkan Nilai Tambah Usaha Tani Kopi Rakyat. Denpasar : 16 -17 Oktober 2002. Pusat Penelitian Kopi dan Kakao Indonesia.

[10] Brooker DB et al . 1974. Drying Cereal Grain. Connecticut: The AVI Publishing Company Inc. Wesport

[11] Broker, Ddab C.W. Hall. 1981 ,.F.W. Bakker Arkem . Droying Cerea Grains. The AVIInc Wesport.Connecticut Pub.Co

[12] Munir, Rinaldi. "Pengolahan Citra Digital dengan Pendetakan Algoritmik". Informatika Bandung, Bandung. 2004. "Pengolahan Citra Digital dengan Pendetakan Algoritmik"

[13] Erlinda, S.,2009. Analisa Terhadap Jumlah Produksi Kopi, Jumlah Ekspor Kopi, Dan Nilai Devisa Kopi Di Indonesia Tahun 1972-2008. Medan. USU Repositori. [6] Resmana. 1999. "Implementasi Fuzzy Logic Pada Microcontoller Untuk Kendali Putaran Motor DC", Proceedings, Industrial Electronic Seminar 1999 (IES'99), Graha Institut Teknologi Sepuluh Nopember, Surabaya, October 27-28, 1999

[14] Hendrik, Roza Susanti (2012) : Karakterisasi aroma kopi menggunakan short time Proseding SNASTIKOM 